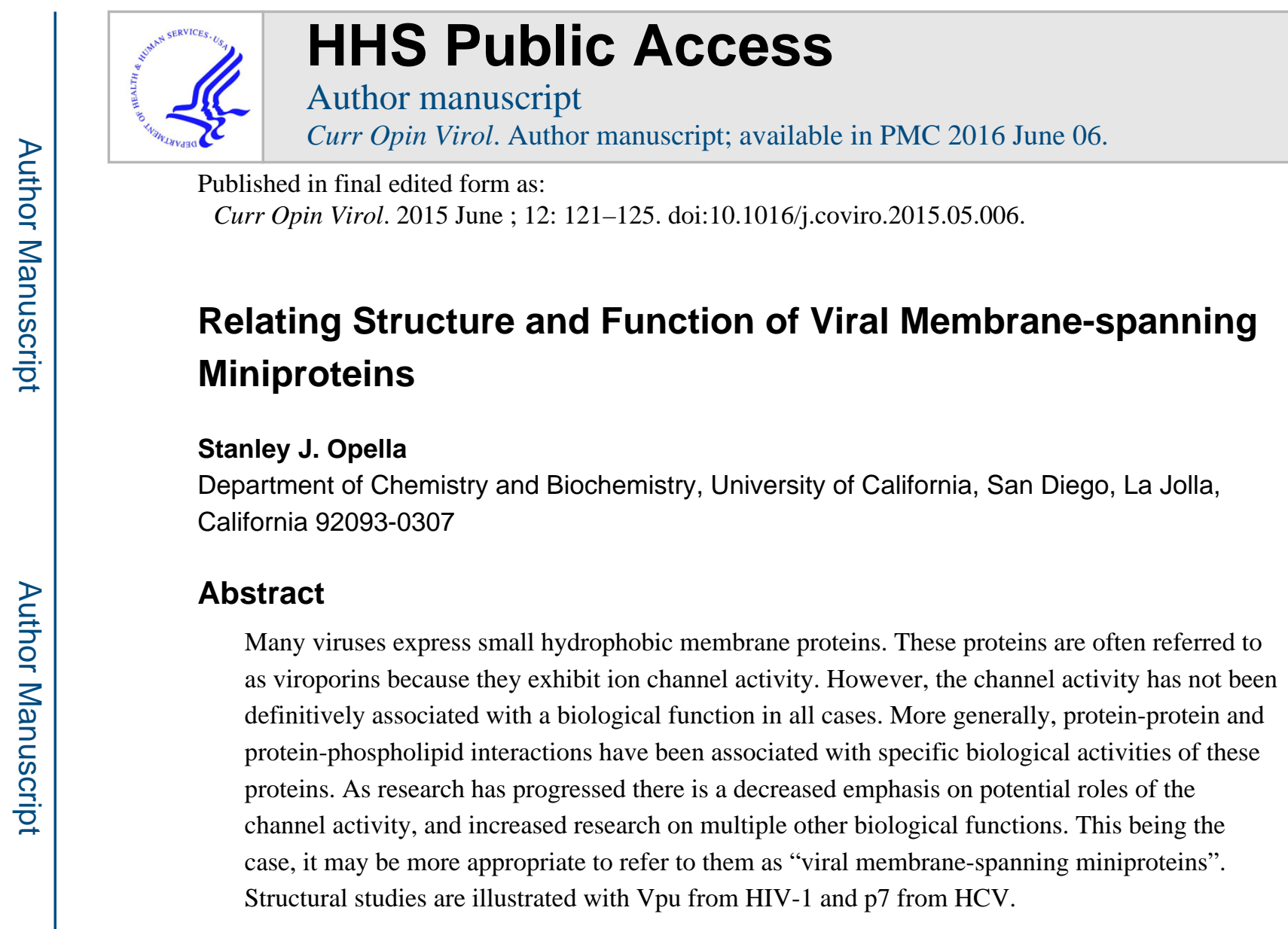

\title{
Introduction
}

Small viral membrane proteins perform multiple biological functions, which are generally associated with much larger proteins. Contributing factors may be the need to take optimal advantage of the limited sequence information encoded in compact viral genomes, and that these proteins are associated with lipid bilayers with different compositions and properties in various organelles, which can influence their structures, interactions, and functions. Here, we utilize two well-characterized examples, virus protein "u" (Vpu) of the human immunodeficiency virus (HIV-1) [1] and $\mathrm{p} 7$ of hepatitis $\mathrm{C}$ virus (HCV) [2], to describe the current state of the structural biology of this class of proteins. Neither of these proteins has been crystallized, therefore nearly all of the experimental structural information available is derived from nuclear magnetic resonance (NMR) spectroscopy. We contrast the properties of these proteins with those of the best studied example; the M2 protein of Influenza, which has a well-defined channel function. The structure of its trans-membrane channel domain has been extensively characterized by NMR spectroscopy, X-ray crystallography, and other physical methods $[3,4]$.

(C) 2015 Published by Elsevier B.V.

Corresponding author: Stanley J. Opella; sopella@ucsd.edu; telephone: 858 822-4820; telefax: 858 822-4821; postal address: Department of Chemistry and Biochemistry, University of California, San Diego, Natural Sciences Building, 9500 Gilman Drive, Mail Code 307, La Jolla, California, 92093-0307 U.S.A.

Publisher's Disclaimer: This is a PDF file of an unedited manuscript that has been accepted for publication. As a service to our customers we are providing this early version of the manuscript. The manuscript will undergo copyediting, typesetting, and review of the resulting proof before it is published in its final citable form. Please note that during the production process errors may be discovered which could affect the content, and all legal disclaimers that apply to the journal pertain. 
Despite the differences in their titles, DiMaio's review entitled "Viral Miniproteins" [5] and that by Nieva, Madan, and Carrasco [6] entitled "Viroporins: Structure and Biological Functions" are concerned with the same class of proteins. Viroporins are strongly associated with having channel activity. DiMaio, in a sense, breaks new ground by providing a more general view of these proteins. This is well justified because these proteins have multiple essential activities; even though in many cases they do display channel activity, it is not always clear if and how it is associated with biological functions. Strebel's review [7] describes functional implications of much of the available structural information on Vpu, including questions about the role of its channel activity. The review by Steinmann and Pietschmann provides essential background on $\mathrm{p} 7$ [8].

\section{NMR of membrane proteins}

Solution NMR is applicable to relatively small membrane proteins in model membrane environments, such as mixed organic solvents, detergent micelles, isotropic bicelles, and recently nanodiscs. Despite their limitations, these environments have been used because they enable the proteins to reorient rapidly enough in solution to yield high-resolution NMR spectra. Caution must be exercised in the interpretation of the results as these non-native environments can affect the properties of the proteins. For example, the commonly used solvent $50 \% \mathrm{TFE} / 50 \%$ water has a propensity to stabilize helices while destabilizing or distorting tertiary and quaternary structure. It may very well be the case that the same sensitivity of the structure to the lipid environment provides a range of functions [9] and makes it difficult to sort out the correct biological structure from the various types of NMR samples that have been studied [10].

Membrane proteins can also be reconstituted into phospholipids. When associated with bilayers, membrane proteins are effectively 'immobilized' on the timescales of the chemical shift and dipole-dipole nuclear spin interactions. Consequently, solid-state NMR methods are required to obtain high-resolution NMR spectra. Under physiological conditions, membrane proteins undergo rotational diffusion about the bilayer normal, which enables the application of rotationally aligned solid-state NMR [11]. This is complementary to other solid-state NMR approaches that measure distances and angles in unoriented samples with the application of magic angle spinning (MAS) $[12,13]$ as well as mechanically or magnetically aligned samples for oriented sample solid-state NMR [14].

\section{Vpu from HIV-1}

HIV-1 has a single-stranded positive-sense RNA genome of $9.8 \mathrm{~kb}$ that is processed to form the structural, regulatory, and envelope proteins characteristic of a retrovirus. In addition it has four accessory proteins, one of which, $\mathrm{Vpu}$, is a small 81-residue membrane protein [1].

The initial structural studies of Vpu were performed by solution NMR in TFE/water on a series of synthetic peptides having between 15 and 50 amino acids [15-19] with sequences corresponded to overlapping sections of the protein. General ideas about the overall architecture of the protein emerged from these studies. More detailed studies required the use of expressed polypeptides because of the opportunities for isotopic labeling [20-24]. From the combination of these studies, a picture of Vpu emerged as having an N-terminal 
hydrophobic trans-membrane helix, which oligomerizes to form channels, and a C-terminal cytoplasmic domain with a helix-loop-helix arrangement. Significantly, the loop contains two conserved serine residues that are phosphorylated.

The combination of expressed polypeptides and phospholipid bilayer samples provides a near-native environment. Marassi et al [25] studied expressed full-length and truncated constructs of $\mathrm{Vpu}$ in phospholipid bilayers by oriented sample solid state NMR, which showed that the protein has two distinct domains. To define the minimum folding units, Ma et al [26] prepared three truncated forms of Vpu and compared their structural and functional properties to those of the full-length protein. Park et al [27] determined the threedimensional structure of the channel-forming trans-membrane domain (VpuTM).

Substitution of alanine at position 18 by a histidine (A18H) has been shown to render HIV-1 infections susceptible to rimantadine [28]. The structure of A18H VpuTM was determined, and compared to that of wild-type Vpu TM [29]. Rotationally aligned studies complement solution NMR studies in yielding a structure for the Vpu monomer (Zhang et al, unpublished results) (Figure 1). This structure is distinguished by having three helical segments, one of which is a hydrophobic membrane-spanning helix that can form a channel; the other two are part of an amphipathic surface domain. Notably, all of the helices can interact with other proteins contributing to the biological functions of $\mathrm{Vpu}$.

In a complementary approach using unoriented samples, Sharpe et al [30] described solidstate magic angle spinning experiments on the $\mathrm{N}$-terminal half of $\mathrm{Vpu}$. Their data indicated that the transmembrane alpha helix extends beyond the hydrophobic core of the bilayer. Lu et al [31] described measurements that provided new constraints on the oligomerization state of $\mathrm{Vpu}$. Their data indicated that a variety of oligomers coexist in phospholipid bilayers. This is also consistent with at least one of Vpu's activities being associated with its forming channels. Do et al applied magic angle spinning solid-state NMR [32] to expressed fulllength Vpu and a construct consisting of residues 372-433 of CD4.

The binding between $\mathrm{Vpu}$ and $\beta$ - TrCP does not require phosphorylation of the serines in the interhelical loop of the cytoplasmic domain of $\mathrm{Vpu}$, however activation of the degradation pathway does. Coadou et al [33-37] used relatively short peptides to elucidate [35] the basis of $\beta$-TrCP recognition. The $\beta$-TrCP-bound structure of phosphorylated Vpu was found to be similar to the structure of the free peptide in solution and to the structure recognized by its antibody. Gharabi-Benarous [36] investigated a 22-amino acid peptide that mimics the phosphorylated Vpu antigen. Phosphorylation of Vpu at sites Ser52 and Ser56 on the DSGXXS motif is required for the interaction of Vpu with the ubiquitin ligase SCF ( $\beta$ $\operatorname{TrCP}$ ) that triggers $\mathrm{CD} 4$ degradation by the proteasome. The peptide residues forming this bend are recognized by a monoclonal antibody. Evrard-Todeschi et al [37] examined the binding and conformation of phosphopeptides to $\beta$-TrCP.

Vpu antagonizes the interferon-induced restriction factor BST-2 (tetherin) by a proteinprotein interaction associated with the helical trans-membrane domains of each protein. Guatelli and Opella [38] have studied the mechanism of how Vpu antagonizes BST-2. They found that this results from an intermolecular interaction that occurs between the single trans-membrane domain in each protein. The antagonism of BST-2 involves a sequence of 
three alanines and a tryptophan spaced at four residue intervals within the Vpu helix. Responsiveness to Vpu involves bulky hydrophobic residues in the C-terminal region of the BST-2 trans-membrane helix that likely fit between the alanines on the interactive face of Vpu. As a result, Vpu and BST-2 form an anti-parallel, lipid-embedded helix-helix interface. Changes in human BST-2 that mimic sequences found in nonhuman primate orthologs unresponsive to $\mathrm{Vpu}$ change the tilt angle of the trans-membrane helix in the lipid bilayer without abrogating its intrinsic ability to interact with $\mathrm{Vpu}$. This provides a mechanism by which HIV-1 evades a key aspect of innate immunity and the species specificity of Vpu using an anti-parallel helix-helix packing model.

A tryptophan residue near the $\mathrm{Vpu} \mathrm{C}$-terminus is important for enhancing virion release. Vpu proteins with the W76G mutation degraded and down regulated BST-2 from the cell surface, yet they inefficiently stimulated virion release. In further NMR studies [39] it was found that the cytoplasmic domain of Vpu specifically interacts with lipids. Paramagnetic relaxation enhancement (PRE) studies show that W76 inserts into the lipid bilayer. These results are consistent with a model whereby W76 anchors the C-terminus of Vpu's cytoplasmic tail to the plasma membrane, enabling the movement of Vpu-bound BST-2 away from viral assembly sites.

\section{p7 from HCV}

$\mathrm{HCV}$ is an enveloped virus with a single-strand RNA genome of approximately $9.6 \mathrm{~kb}$, which is translated into a single 3000-amino acid polyprotein that is cleaved to yield ten proteins [40]. Notably, the nucleotide sequence for the 63-residue membrane protein, $\mathrm{p} 7$, is sandwiched between those that code for the three structural protein that constitute the virion and the six nonstructural proteins that constitute the replication complex and perform other functions. p7 has been shown to be essential for efficient virus particle assembly and release [41], but not RNA replication [42]. p7 is generally categorized as a viroporin because it oligomerizes to form ion channels. It has been proposed that it is activated at low $\mathrm{pH}$ and dissipates acidification of a secretory compartment $[8,40]$.

Griffin et al. described the oligomerization state of $\mathrm{p} 7$ as a hexamer [43]. Clarke et al. published a study on a FLAG-tagged p7 construct [44] where they conducted cross-linking studies and observed a predominately heptameric complex. Subsequently, Luik et al. [45] showed that the p7 subtype JFH-1 reconstituted in DHPC detergent micelles gave up to 6 bands after cross-linking in the SDS-PAGE analysis, suggesting a hexameric oligomer. Chandler et al have performed simulations that yield stable hexameric and heptameric channels [46].

Saint et al [47] synthesized a polypeptide with the sequence of the 63-residue $\mathrm{p} 7$ protein. They were able to obtain well-resolved NMR spectra in TFE/water but not detergent micelles. Montserrat et al [48] determined the secondary structure elements of the monomeric form of $\mathrm{p} 7 \mathrm{in} \mathrm{TFE} /$ water, suggesting the presence of a helix-loop-helix 'hairpin' structure.

Cook et al performed initial NMR studies on expressed $\mathrm{p} 7$ in phospholipid bilayers and micelles $[49,50]$ and obtained a similar helix-loop-helix arrangement of the secondary 
structure of the protein. The protein contained helical segments tilted approximately $10^{\circ}$ and $25^{\circ}$ relative to the bilayer normal. In another study, they [51] described a series of solution NMR experiments that showed $\mathrm{p} 7$ has a range of dynamic properties as well as stable structural segments. The 63 -amino acid protein has a remarkably complex structure made up of seven identifiable sections, four of which are helical segments with different tilt angles and dynamics. More definitively, Cook et al [52] determined the three-dimensional structure of $\mathrm{p} 7$ in DHPC micelles by solution NMR and in DMPC bilayers by solid-state NMR (Figure 1).

OuYang et al [53,54] determined the structure of $\mathrm{p} 7$ in DPC micelles by solution NMR. Their structure is an unusual hexameric assembly, where the individual $\mathrm{p} 7$ monomers not only interact with their immediate neighbors but also reach more distant neighbors. Their structure contains three rather than two helical segments and differs from the prior structures in other ways. The substantial differences in structure contrast with the similarities of the primary sequences and especially the corresponding hydropathy plots. Further research is required to sort out how the differences in structure are consistent with the similarities in function [55].

The structure of $\mathrm{p} 7$ has been determined in five different conditions, yielding in each case a different structure for the protein. This is typical for membrane proteins, because of their sensitivity to the solvent or lipid environment. The structure of $\mathrm{p} 7$ has been determined four times by solution NMR, twice in organic solvents (TFE/water [48] and methanol [56]) and twice in detergent micelles (DHPC [52] and DPC [53]). Recently, the structure of p7 shown in Figure 1 has been determined in the near-native environment of DMPC bilayers by solidstate NMR (Cook et al, unpublished results). Resolution of these differences will require the use of a common membrane environment to sort out the influence of the environment on the structure and dynamics of the protein. The structures of the monomers will play a crucial role in identifying whether there is a biologically functional form of the oligomeric channels. At present, there is less evidence of other functions of $\mathrm{p} 7$.

\section{Conclusions}

Although M2 of Influenza is the best characterized viroporin, structurally only the properties of the trans-membrane channel-forming domain are known with certainty. Progress is being made on the full-length protein [57,58]. In contrast, Cook et al [59] compared the properties of p7 and Vpu. The purified proteins were studied in the model membrane environments of micelles by solution NMR spectroscopy and in phospholipid bilayers by solid-state NMR spectroscopy. The resulting structural findings enabled comparisons to be made between the two proteins, demonstrating that they have quite different architectures. Most notably, Vpu has one trans-membrane helix and p7 has two trans-membrane helices. In addition there are significant differences in the structures and dynamics of their internal loop and terminal regions. It is difficult to classify these two proteins in the same structural family, since their structures are so different. However, there are some similarities in their functions, and, like M2 of Influenza, they are small viral membrane proteins. 


\section{Acknowledgments}

We thank Dr. Ye Tian for help with computer graphics and Jasmina Radoicic with editorial assistance. The research described in this article that was performed at the University of California, San Diego was supported by grants P41EB002031, R01GM099986, R01GM066978, and P01AI074805 from the National Institutes of Health. It utilized the Biotechnology Resource Center (BTRC) for NMR Molecular Imaging of Proteins at the University of California, San Diego supported by the National Institute of Biomedical Imaging and Bioengineering.

\section{References}

1. Strebel K, Klimkait T, Martin M. A novel gene of HIV1, vpu, and its 16-kilodalton product. Science. 1988; 241:1221-1223. [PubMed: 3261888]

2. Carrere-Kremer S, Montpellier-Pala C, Cocquerel L, Wychowski C, Penin F, Dubuisson J. Subcellular localization and topology of the $\mathrm{p} 7$ polypeptide of hepatitis C virus. J Virol. 2002; 76:3720-3730. [PubMed: 11907211]

3. Hong M, DeGrado WF. Structural basis for proton conduction and inhibition by the influenza M2 protein. Protein Sci. 2012; 21:1620-1633. [PubMed: 23001990]

4. Cross TA, Dong H, Sharma M, Busath DD, Zhou HX. M2 protein from influenza A: from multiple structures to biophysical and functional insights. Current opinion in virology. 2012; 2:128-133. [PubMed: 22482709]

5**. DiMaio D. Viral miniproteins. Annu Rev Microbiol. 2014; 68:21-43. The author reviews small viral membrane proteins in a general context, putting their channel activity in perspective with their other biological activities. [PubMed: 24742054]

$6^{* *}$. Nieva J, Madan V, Carrasco L. Viroporins: structure and biological functions. Nat Rev Microbiol. 2012; 10:563-574. The authors are among the earliest investigators to identify the presence and channel activities of viroporins. An authoritative review. [PubMed: 22751485]

7*. Strebel K. HIV-1 Vpu - an ion channel in search of a job. Biochim Biophys Acta. 2014; 1838:1074-1081. A timely review of Vpu by the investigator who discovered the protein (see reference 1). Vpu is a potential drug target. [PubMed: 23831603]

8. Steinmann E, Pietschmann T. Hepatitis C virus p7 - A viroporin crucial for virus assembly and an emerging target for antiviral therapy. Viruses. 2010; 2:2078-2095. [PubMed: 21994720]

9. Gan S, Surya W, Vararattanavech A, Torres J. Two different conformations in hepatitis C virus p7 proein account for proton transport and dye release. PLOS One. 2014; 9:e78494. [PubMed: 24409277]

10. Cross TA, Sharma M, Myunggi Y, Zhou HX. Influence of solubilizing environments on membrane protein structures. Trends Biochemical Sciences. 2011; 36:117-125.

$11^{* *}$. Opella SJ. Structure determination of membrane proteins in their native phospholipid bilayer environment by rotationally aligned solid-state NMR spectroscopy. Accounts of chemical research. 2013; 46:2145-2153. A general method for determining the structures of membrane proteins I phospholipid bilayers under near-native conditions. [PubMed: 23829871]

12. Su Y, Andreas L, Griffin RG. Magic Angle Spinning NMR of Proteins: High-Frequency Dynamic Nuclear Polarization and H Detection. Annual review of biochemistry. 2015

13. Baker LA, Folkers GE, Sinnige T, Houben K, Kaplan M, van der Cruijsen EA, Baldus M. Magicangle-spinning solid-state NMR of membrane proteins. Methods in enzymology. 2015; 557:307328. [PubMed: 25950971]

14. Opella SJ, Marassi FM. Structure determination of membrane proteins by NMR spectroscopy. Chem Rev. 2004; 104:3587-3606. [PubMed: 15303829]

15. Henklein P, Schubert U, Kunert O, Klabunde S, Wray V, Kloppel KD, Kiess M, Portsmann T, Schomburg D. Synthesis and characterization of the hydrophilic C-terminal domain of the human immunodeficiency virus type 1-encoded virus protein U (Vpu). Peptide research. 1993; 6:79-87. [PubMed: 8387359]

16. Wray V, Federau T, Henklein P, Klabunde S, Kunert O, Schomburg D, Schubert U. Solution structure of the hydrophilic region of HIV-1 encoded virus protein $\mathrm{U}(\mathrm{Vpu})$ by $\mathrm{CD}$ and $1 \mathrm{H}$ NMR spectroscopy. International journal of peptide and protein research. 1995; 45:35-43. [PubMed: 7775007] 
17. Federau T, Schubert U, Flossdorf J, Henklein P, Schomburg D, Wray V. Solution structure of the cytoplasmic domain of the human immunodeficiency virus type 1 encoded virus protein $\mathrm{U}(\mathrm{Vpu})$. International journal of peptide and protein research. 1996; 47:297-310. [PubMed: 8738656]

18. Wray V, Kinder R, Federau T, Henklein P, Bechinger B, Schubert U. Solution structure and orientation of the transmembrane anchor domain of the HIV-1 encoded virus protein $\mathrm{U}$ by highresolution and solid-state NMR spectdroscopy. Biochemistry. 1999; 38:5272-5282. [PubMed: 10213635]

19. Henklein P, Kinder R, Schubert U, Bechinger B. Membrane interactions and alignment of structures within the HIV-1 Vpu cytoplasmic domain: effect of phosphorylation of serines 52 and 56. FEBS letters. 2000; 482:220-224. [PubMed: 11024464]

20. Willbold D, Hoffmann S, Rosch P. Secondary structure and tertiary fold of the human immunodeficiency virus protein U ( Vpu) cytoplasmic domain in solution. Eur J Biochem. 1997; 245

21. Lemaitre V, Willbold D, Watts A, Fischer WB. Full length Vpu from HIV-1: Combining molecular dynamics simulations with NMR spectroscopy. J Biomol Struct Dynam. 2006; 23:485496.

22. Wittlich M, Koenig BW, Willbold D. Structural consequences of phosphorylation of two serine residues in the cytoplasmic domain of HIV-1 VpU. J Pept Sci. 2008; 14:804-810. [PubMed: 18186541]

23. Wittlich M, Koenig BW, Stoldt M, Schmidt H, Willbold D. NMR structural characterization of HIV-1 virus protein $U$ cytoplasmic domain in the presence of dodecylphosphatidylcholine micelles. FEBS J. 2009; 276:6560-6575. [PubMed: 19804408]

24. Wittlich M, Thiagarajan P, Koening B, Hartmann R, Willbold D. NMR structure of the transmembrane and cytoplasmic domains of human CD4 in micelles. BBA. 2010; 1798:122-127. [PubMed: 19781520]

25. Marassi FM, Ma C, Gratkowski H, Straus SK, Strebel K, Oblatt-Montal M, Montal M, Opella SJ. Correlation of the structural and functional domains in the membrane protein Vpu from HIV-1. Proc Natl Acad Sci U S A. 1999; 96:14336-14341. [PubMed: 10588706]

26. Ma C, Marassi FM, Jones DH, Straus SK, Bour S, Strebel K, Schubert U, Oblatt-Montal M, Montal M, Opella SJ. Expression, purification, and activities of full-length and truncated versions of the integral membrane protein Vpu from HIV-1. Protein Sci. 2002; 11:546-557. [PubMed: 11847278]

27. Park SH, Mrse AA, Nevzorov AA, Mesleh MF, Oblatt-Montal M, Montal M, Opella SJ. Threedimensional structure of the channel-forming trans-membrane domain of virus protein " $u$ " (Vpu) from HIV-1. J Mol Biol. 2003; 333:409-424. [PubMed: 14529626]

28. Hout D, Gomez L, Pacyniak E, Miller J, Hill M, Stephens E. A single amino acid substitution within the trans-membrane domain of the human immunodeficiency virus type $1 \mathrm{Vpu}$ protein renders simian-human immunodeficiency virus (SHIV(KU-1bMC33)) susceptible to rimantadine. Virology. 2006; 348:449-461. [PubMed: 16458946]

29. Wang Y, Park SH, Tian Y, Opella SJ. Impact of histidine residues on the transmembrane helices of viroporins. Molecular membrane biology. 2013; 30:360-369. [PubMed: 24102567]

30. Sharpe S, Yau W, Tycko R. Structure and dynamics of the HIV-1 Vpu transmembrane domain revealed by solid-state NMR with magic-angle spinning. Biochemistry. 2006; 45:918-933. [PubMed: 16411768]

31. Lu JX, Sharpe S, Ghirlando R, Yau WM, Tycko R. Oligomerization state and supramolecular structure of the HIV-1 Vpu protein transmembrane segment in phospholipid bilayers. Protein Sci. 2010; 19:1877-1896. [PubMed: 20669237]

32. Do HQ, Wittlich M, Gluck JM, Mockel L, Willbold D, Koenig BW, Heise H. Full-length Vpu and human CD4(372-433) in phospholipid bilayers as seen by magic angle spinning NMR. BIol Chem. 2013; 394:1453-1463. [PubMed: 23863698]

33. Coadou G, Evrard-Todeschi N, Gharbi-Benarous J, Benarous R, Girault JP. Conformational analysis by NMR and molecular modelling of the 41-62 hydrophilic region of HIV-1 encoded virus protein $\mathrm{U}(\mathrm{Vpu})$. Effect of the phosphorylation on sites 52 and 56. Chimie. 2001; 4:751-758. 
34. Coadou G, Evrard-Todeschi N, Gharbi-Benarous J, Benarous R, Girault JP. HIV-1 encoded virus protein $\mathrm{U}(\mathrm{Vpu})$ solution structure of the 41-62 hydrophilic region containing the phosphorylated sites Ser52 and Ser56. International journal of biological macromolecules. 2002; 30:23-40. [PubMed: 11893391]

35. Coadou G, Gharbi-Benarous J, Megy S, Bertho G, Evrard-Todeschi N, Segeral E, Benarous R, Girault JP. NMR studies of the phosphorylation motif of the HIV-1 protein Vpu bound to the Fbox protein beta-TrCP. Biochemistry. 2003; 42:14741-14751. [PubMed: 14674748]

36. Gharbi-Benarous J, Bertho G, Evrard-Todeschi N, Coadou G, Megy S, Delaunay T, Benarous R, Girault JP. Epitope mapping of the phosphorylation motif of the HIV-1 protein Vpu bound to the selective monoclonal antibody using TRNOESY and STD NMR spectroscopy. Biochemistry. 2004; 43:14555-14565. [PubMed: 15544326]

37. Evrard-Todeschi N, Gharbi-Benarous J, Bertho G, Coadou G, Megy S, Benarous R, Girault JP. NMR studies for identifying phosphopeptide ligands of the HIV-1 protein Vpu binding to the Fbox protein beta-TrCP. Peptides. 2006; 27:194-210. [PubMed: 16165251]

$38^{* *}$. Skasko M, Wang Y, Tian Y, Tokarev A, Munguia J, Ruiz A, Stephens E, Opella SJ, Guatelli J. HIV-1 Vpu protein antagonizes innate restriction factor BST-2 via lipid-embedded helix-helix interactions. The Journal of biological chemistry. 2012; 287:58-67. A combination of molecular biology and NMR spectroscopy is used to describe how Vpu antagonizes BST2 and enhances the release of virus particles from infected cells. [PubMed: 22072710]

39. Lewinski M, Jafari M, Zhang H, Opella S, Guatelli J. Membrane anchoring by a C-terminal tryptophan enables HIV-1 Vpu to displace BST2 from sites of viral assembly. J Biol Chem. 2015; 290:10919-10933. [PubMed: 25759385]

40. Moradpour D, Penin F. Hepatitis C virus proteins: from structure to function. Curr Top Microbiol Immunol. 2013; 369:113-142. [PubMed: 23463199]

41. Gentzsch J, Brohm C, Steinmann E, Friesland M, Menzel N, Vieyres G, PMP, Fretzen A, Kaderali L, Pietschmann T. Hepatitis C virus p7 is critical for capsid assembly and envelopment. PLOS Pathogens. 2013; 9:e1003355. [PubMed: 23658526]

42. Sakai A, Claire MS, Faulk K, Govindarajan S, Emerson SU, Purcell RH, Bukh J. The p7 polypeptide of hepatitis $\mathrm{C}$ virus is critical for infectivity and contains functionally important genotype-specific sequences. Proc Natl Acad Sci U S A. 2003; 100:11646-11651. [PubMed: 14504405]

43. Griffin SDC, Beales LP, Clarke DS, Worsfold O, Evans SD, Jaeger J, Harris MPG, Rowlands DJ. The $\mathrm{p} 7$ protein of hepatitis $\mathrm{C}$ virus fomrs an ion channeel that is blocked by the antiviral drug amantadine. FEBS Lett. 2003; 535:34-38. [PubMed: 12560074]

44. Clarke D, Griffin S, Beales L, Geais CS, Burgess S, Harris M, Rowlands D. Evidence for the formation of a heptameric ion channel complex by the hepatitis $\mathrm{C}$ virus $\mathrm{p} 7$ protein in vitro. The Journal of biological chemistry. 2006; 281:37057-37068. [PubMed: 17032656]

45. Luik P, Chew C, Aittoniemi J, Chang J, Wentworth P, Dwek RA, Biggin PC, Venien-Bryan C, Zitzmann N. The 3-dimensional structure of a hepatitis $\mathrm{C}$ virus $\mathrm{p} 7$ ion channel by electron microscopy. Proc Natl Acad Sci U S A. 2009; 106:12712-12716. [PubMed: 19590017]

46. Chandler D, Penin F, Schulten K, Chipot C. The p7 protein of hepatitis C virus forms structurally plastic, minimalist ion channels. PLOS Comp Biol. 2012; 8:e1002702.

47. Saint N, Montserret R, Chipot C, Penin F. Structural and functional analysis of the HCV p7 protein. Methods Mol Biol. 2009; 510:125-143. [PubMed: 19009258]

48. Montserret R, Saint N, Vanbelle C, Salvay AG, Simorre J-P, Ebel C, Sapay N, Renisio J-G, Bockmann A, Steinmann E, et al. NMR structure and ion channel activity of the p7 protein from hepatitis C virus. The Journal of biological chemistry. 2010; 285:31446-31461. [PubMed: 20667830]

49. Cook GA, Opella SJ. NMR studies of p7 protein from hepatitis C virus. Eur Biophys J. 2010; 39:1097-1104. [PubMed: 19727701]

50. Cook GA, Stefer S, Opella SJ. Expression and purification of the membrane protein $\mathrm{p} 7$ from hepatitis C virus. Biopolymers. 2011; 96:32-40. [PubMed: 20560141] 
51. Cook GA, Opella SJ. Secondary structure, dynamics, and architecture of the p7 membrane protein from hepatitis C virus by NMR spectroscopy. Biochim Biophys Acta - Biomembranes. 2011; 1808:1448-1453.

52. Cook GA, Dawson LA, Tian Y, Opella SJ. Three-dimensional structure and interaction studies of hepatitis $\mathrm{C}$ virus $\mathrm{p} 7$ in 1,2-dihexanoyl-sn-glycero-3-phosphocholine by solution nuclear magnetic resonance. Biochemistry. 2013; 52:5295-5303. [PubMed: 23841474]

53. OuYang B, Xie S, Berardi MJ, Zhao X, Dev J, Yu W, Sun B, Chou JJ. Unusual architecture of the p7 channel from hepatitis C virus. Nature. 2013; 498:521-525. [PubMed: 23739335]

54. OuYang B, Chou JJ. The minimalist architectures of viroporins and their therapeutic implications. Biochim Biophys Acta. 2014; 1838:1058-1067. [PubMed: 24055819]

55. Kalita MM, Griffin S, Chou JJ, Fischer WB. Genotype-specific differences in structural features of hepatitis C virus (HCV) p7 membrane protein. Biochim Biophys Acta. 2015; 1848:1383-1392. [PubMed: 25772504]

56. Foster T, Thompson G, Kalverda A, Kankanala J, Bentham M, Wtherill L, Thompson J, Barker A, Clarke D, Noerenberg M, et al. Structure-guided design affirms inhibitors of hepatitis C virus p7 as a viable class of antivirals targeting virion release. Hepatology. 2014; 59:408-422. [PubMed: 24022996]

57. Miao Y, Qin H, Fu R, Sharma M, Can TV, Hung I, Luca S, Gor'kov PL, Brey WW, Cross TA. M2 proton channel structural validation from full-length protein samples in synthetic bilayers and E.coli membranes. Angewandte Chemie. 2012; 51:8383-8386. [PubMed: 22807290]

58. Liao SY, Fritzsching KJ, Hong M. Conformational analysis of the full-length M2 protein of the influenza A virus using solid-state NMR. Protein Sci. 2013; 22:1623-1638. [PubMed: 24023039]

59. Cook GA, Zhang H, Park SH, Wang Y, Opella SJ. Comparative NMR studies demonstrate profound differences between two viroporins: p7 of HCV and Vpu of HIV-1. BBA. 2011; 1808:554-560. [PubMed: 20727848] 


\section{Highlights}

- Many viruses express small membrane proteins.

- Although generally known as viroporins these the role of channel activity is generally undefined.

- The structures of these proteins are affected by the membrane environment.

- They have functions in the viral infection and release processes. 


\section{Vpu}

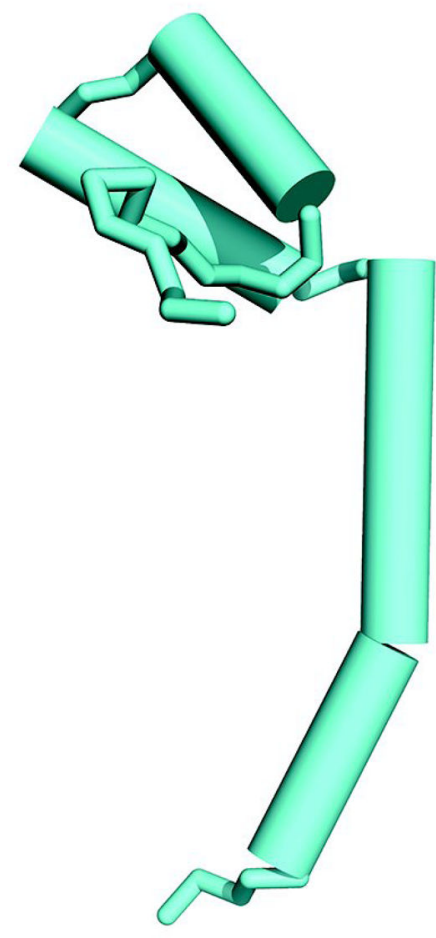

p7

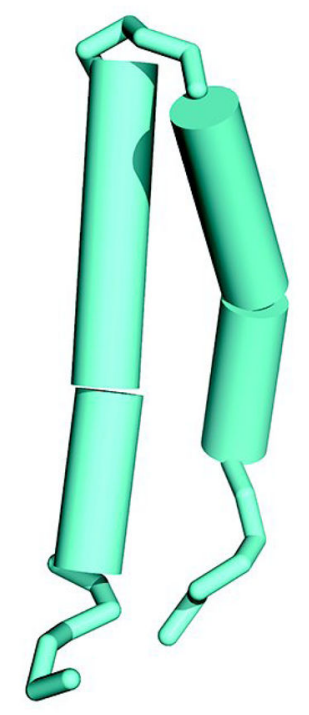

Figure 1.

Structural models of Vpu (left) and p7 (right) derived from NMR data (unpublished results). 